\title{
Exploring How Gender, Self-Identified Personality Attributes, Mathematics Identity, and Gender Identification Contribute to College Students' STEM Career Goals
}

\author{
Jennifer Cribbs ${ }^{\mathrm{a}}$ and Katrina Piatek-Jimenez ${ }^{\mathrm{b}}$ \\ Corresponding author: Jennifer Cribbs (jennifer.cribbs@okstate.edu)

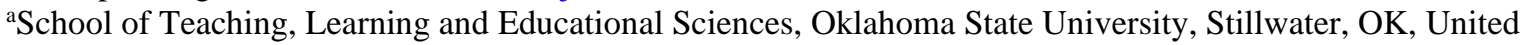 \\ States \\ ${ }^{\text {b}}$ Department of Mathematics, Central Michigan University, Mount Pleasant, MI, United States
}

Keywords: gender, gender identification, mathematics identity, self-identified personality attributes, STEM career goals

\begin{abstract}
In this study we surveyed 958 college students enrolled in Pre-calculus, Calculus I, and Calculus II courses at two different public universities in the United States to explore STEM career goals with self-identified personality attributes, mathematics identity, and strength of gender identification. We analyzed the results of our data by gender, using a series of Wilcoxon Rank Sum tests, and correlation. We found that, for both genders, certain self-identified personality attributes were more common amongst college students who selected a science, technology, engineering, or mathematics (STEM) career goal as compared to college students who did not select a STEM career goal. We also found a weak correlation between the strength of one's gender identification and mathematics identity. In this paper we report our findings and reflect on our results with regards to the shortage of women entering STEM careers.
\end{abstract}

\section{Introduction}

Many STEM (Science, Technology, Engineering, and Mathematics) jobs in the United States go unfulfilled each year due to a shortage of qualified candidates (Atkinson, 2013). Furthermore, in recent years, while STEM jobs have been growing at a faster rate than jobs outside of STEM fields (Langdon, McKittrick, Beede, Khan, \& Doms, 2011), the number of individuals earning degrees in these fields have effectively remained unchanged. For instance, the percentage of students earning bachelor's degrees in science and engineering fields has only increased by about $2 \%$ between the years 2006 and 2016, and in certain subfields, such as computer science, the numbers have actually decreased by $2 \%$ during that same timeframe (National Science Foundation, National Center for Science and Engineering Statistics [NSF, NCSES], 2019). The statistics for master's and doctoral degrees are similar, with the Organisation for Economic Co-operation and Development (OECD, 2011) reporting the United States as awarding one of the lowest percentages of doctoral degrees in the field of science and engineering when compared with seventeen other countries. In addition, there is evidence that when compared with other countries (Germany, China, Japan), the United States awards fewer undergraduate degrees in science and engineering (National Academy of Sciences [NAS], 2005). Given that the STEM workforce has a large impact on the nation's 
economic growth, this shortage of individuals studying STEM disciplines and entering STEM careers is a cause for national concern in the United States (Langdon et al., 2011).

As the demand for qualified candidates in the STEM disciplines continues to grow, it is important to note that women remain underrepresented in many of these fields. In 2015, although women constituted $46.9 \%$ of the entire United States workforce and held $50.9 \%$ of all professional and managerial careers, women were only $29 \%$ of those employed in STEM careers $^{1}$ (NSF, NCSES, 2019). In addition, recent trends indicate that the percentage of women being awarded undergraduate and graduate degrees in computer science, mathematics and statistics, and physical sciences has declined in the United States (NSF, NCSES, 2019). Furthermore, many countries outside of the United States also experience this underrepresentation of women in STEM fields. For example,

only 5\% of 15-year-old girls in OECD countries, on average, expect a career in engineering and computing, while 18\% of boys expect a career in these fields... and $73 \%$ of all graduates in the fields of engineering, manufacturing and construction are men (OECD, 2012, p. 73).

Although these statistics show that there continues to be an underrepresentation of women in certain STEM fields, they do not provide us insight as to why these trends exist. In a report published by the Australian Council of Learned Academies comparing countries with regard to STEM education, the authors state that a primary goal for the STEM field is not solely growing the field, but in deepening and broadening the field so that it is accessible for all students, including those who are currently underrepresented (Marginson, Tytler, Freeman, \& Roberts, 2013). While there are many perspectives as to why this gender discrepancy occurs, a substantial body of research clearly suggests that the reasons are societal rather than biological (Augustine et al., 2010). For this current study, we build from prior work to better understand underlying factors (self-identified personality attributes, mathematics identity, and strength of gender identification) that could be contributing to students' goals to pursue a STEM career.

The following three research questions were used to guide this study:

1) Do women who pursue STEM careers identify with different self-identified personality attributes than women who do not pursue STEM careers?

2) Do men who pursue STEM careers identify with different self-identified personality attributes than men who do not pursue STEM careers?

3) Is the strength of college students' gender identification correlated with their mathematics identity?

\section{Literature Review}

\section{Gender Stereotypes and Self-Identified Personality Attributes}

In particular, our study is concerned with the role that gender plays in the expectations and choices an individual makes. It is important to discuss gender stereotypes when discussing self-identified personality attributes because these stereotypes may contribute to individuals' perceptions of themselves and the particular personality attributes they may believe they need

\footnotetext{
${ }^{1}$ NSF's tables refer to S\&E careers, which stands for 'Science and Engineering' careers. Under this category, they include careers such as psychologist and social scientist, which are not traditionally considered STEM careers. In the statistics that we are reporting, we are considering only those careers that are traditionally seen as STEM careers, such as life scientist, physical scientist, mathematical scientist, computer and information scientist, and engineering occupations. The same is true for the statistics we report for degrees earned.
} 
to adopt in order to successfully participate in STEM careers. Research notes that parents (Gunderson, Ramirez, Levine, \& Beilock, 2012) and teachers (Helwig, Anderson, \& Tindal, 2001) hold different beliefs about males' and females' abilities in mathematics. Scholars have noted connections between individuals' personality attributes and career choice (BuddebergFischer, Klaghofer, Abel, \& Buddeberg, 2006). Furthermore, Luyckx, Soenens, and Goossens (2006) found correlations between an individual's identity and personality traits (e.g., openness, agreeableness, conscientiousness). The connections noted in literature are important to consider as individuals may not want to participate in a career that requires them to abandon or change how they view themselves. For example, if being a mathematician is viewed as being "odd, obsessional, geeky and possibly even insane" (Epstein, Mendick, \& Moreau, 2010, p. 55) and being a scientist means you wear glasses, a lab coat, and have crazy hair (Fralick, Kearns, Thompson, \& Lyons, 2009), individuals might not want to adopt these attributes that could be in direct opposition to their self-perception. In turn, this perception of what it means to be a mathematician or scientist could negatively influence their interest in STEM careers. With mathematics and science fields being equated with being male (Steele, 2003), women might have additional stereotypes to overcome in order to pursue a STEM career. These stereotypes about individuals in STEM fields can act as a barrier to women pursuing STEM careers, as is evident in research noting the connection between gender stereotypes and students' STEM career goals (Makarova, Aeschlimann, \& Herzog, 2019).

\section{Mathematics Identity}

Another factor that we explored in this study is mathematics identity (i.e., how individuals see themselves based upon their perceptions and navigation of everyday experiences with mathematics) because it has been found to be linked to students' persistence and attrition in science (Hazari, Sonnert, Sadler \& Shanahan, 2010), engineering (Godwin, Potvin, Hazari, \& Lock, 2016), and mathematics (Cribbs, Hazari, Sadler, \& Sonnert, 2015; Piatek-Jimenez, 2008). For example, Hill and colleagues state "we can encourage students to stay in engineering by helping them associate a perceived engineering identity with their personal identity and demonstrating the value of this association" (2010, p. 300). When students feel as if they need to forfeit their own identities to engage in mathematics, they are less likely to continue to pursue mathematics. Mathematics identity is unique in that it relates to other STEM identities (Godwin, et al., 2016) and career goals (Cribbs, Cass, Hazari, Sadler, \& Sonnert, 2016). For this reason, mathematics identity is a particularly powerful construct for exploring students' career goals. It is also important to make clear that there are multiple approaches to exploring mathematics identity. The way we chose to use the construct of mathematics identity in this study aligns with the core identity perspective of mathematics identity, which captures an enduring sense of self with respect to mathematics (Cobb \& Hodge, 2010). This approach is particularly useful when exploring identity with undergraduate students who have accumulated a variety of mathematical experiences over the years.

\section{Gender Identification}

The final factor we explored is strength of gender identification (i.e., the degree in which an individual identifies with their gender) because of its connection to gender stereotype threat. For example, research by Kiefer and Sekaquaptewa (2007) links gender identification to implicit gender stereotyping, which influences an individual's performance and interest in pursuing math-related fields. Their study's results were similar to prior work indicating that college women who report higher levels of gender identification perform worse than men on a mathematics assessment (Schmader, 2002). Because there are gender stereotypes regarding STEM careers, considering how strongly individuals identify with their gender could be 
important in considering their mathematics identity and career goals. Other scholars found that higher levels of gender identification were linked to lower levels of science identity for women, while the opposite was found for men, with men who report higher levels of gender identification also reporting higher levels of science identity (Cundiff, Vescio, Loken, \& Lo, 2013). These studies highlight potential effects that gender stereotypes can have on individuals' performance and identity, which may in turn affect career goals. By exploring students' self-identified personality attributes, mathematics identity, and strength of gender identification, we hope to develop a better understanding of potential underlying stereotypes and how expectations and identities interact to influence students' career goals.

\section{Instrumentation}

The survey was developed to collect student demographic information, career goals, selfidentified personality attributes, mathematics identity, and strength of gender identification. Demographic information included questions about math course enrollment, gender, race, class standing, and age. Students were also asked to select one of the 14 options that best reflected their current career goal.

\section{Mathematics Identity}

Mathematics identity was measured with 13 items drawing from prior research (Cribbs et al., 2015). These items correlated with three underlying sub-constructs (interest, recognition, and competence/performance), consistently shown to be important components for exploring content-specific identity with undergraduate students (Godwin et al., 2016; Hazari et al., 2010; Lock, Hazari, \& Potvin, 2019), that together create a proxy for measuring mathematics identity. An example of items within this construct include: 'I enjoy learning math' - interest, 'I see myself as a math person' - recognition, and 'I am confident I can understand math in class' - competence/performance.

\section{Self-Identified Personality Attributes}

The 44 items to assess the participants' self-identified personality attributes drew from several studies focused on gender stereotypes. The primary list of items was pulled from Ely's (1995) study exploring potential stereotypes and differences in how men and women self-identified with selected personality attributes in the workplace. Items also drew from more current literature with undergraduate women mathematics students (Piatek-Jimenez, 2015). These items included a variety of statements such as ' $I$ am creative' and ' $I$ am athletic'.

\section{Gender Identification}

Lastly, four items drawing from prior work were used to measure strength of gender identification, which included statements such as 'being a woman/man is an important part of my life' and 'being a woman/man has a lot to do with how I feel about myself' (Jones, Ruff, \& Paretti, 2013; Luhtanen \& Crocker, 1992).

The items measuring mathematics identity and self-identified personality attributes used a Likert-scale of 1 , 'Strongly disagree', to 7, 'Strongly agree' and the strength of gender identification items used a Likert-scale of 1, 'Strongly disagree', to 5, 'Strongly agree.'

Content validity was ensured by: 1) drawing from literature related to personality attributes, mathematics identity, and strength of gender identification (Cribbs et al., 2015; Ely, 1995; Jones, Ruff, \& Paretti, 2013; Luhtanen \& Crocker, 1992; Piatek-Jimenez, 2015), 2) conducting a pilot test with survey items related to personality attributes and gender 
stereotyping, and 3) conducting a pilot test with the completed survey. The initial pilot test also included a series of focus group sessions in order to further refine the survey items. Both pilot tests were conducted with college students enrolled in mathematics and mathematics education courses at the universities where the study was conducted.

\section{Method}

This study collected data from two different universities in the northeast region of the United States. Both universities are public, medium-sized, regional institutions, however, one university is located in a rural setting and the other in a city. Surveys were administered to students enrolled in Pre-calculus, Calculus I, and Calculus II courses, yielding 958 completed surveys. These surveys were completed by the students in person via a physical copy of the survey, administered in the classroom over the course of one academic semester. Thirty-nine percent of respondents identified as female and $61 \%$ identified as male. In terms of race and ethnicity, $84 \%$ self-identified as White, $5 \%$ as Asian, $4 \%$ as Black, $4 \%$ as other, $2 \%$ as multicultural, and less than $1 \%$ as Pacific Islander, with $1 \%$ not responding. Five percent of the participants self-identified as Hispanic. Ninety-four percent of the participants indicated they were between the ages of 18 and $25,3 \%$ of the participants indicated they were between the ages of 26 and 35, less than $1 \%$ indicated they were between 36 and 45, with $3 \%$ not responding. Finally, when asked about class standing, 54\% of participants indicated they were in their first year of college, $24 \%$ indicated they were second year students, $15 \%$ indicated they were third year students, 5\% indicated they were fourth year students, $2 \%$ indicated "Other", and less than $1 \%$ indicated they were a graduate student.

\section{Data Analysis}

All analyses were conducted with R statistical software (R Core Team, 2016). A Hawkins test determined that the data were not normally distributed; however, data were completely missing at random. Although only $0.8 \%$ of data were missing, random imputation (random.imp; Gelman \& Hill, 2006) of missing values was performed to create a complete data vector for variables used in the analysis.

\section{Research Questions 1 and 2}

In order to determine if self-identified personality attributes differed based on career goals and gender, a series of Wilcoxon Rank Sum tests were performed to address research questions 1 and 2. This nonparametric analysis was appropriate given that data were not normally distributed. Table 1 details the possible career goals available on the survey and the corresponding number of responses. The STEM and Non-STEM participants served as the two groups being compared for both research questions. As participants who selected mathematics teacher or science teacher as their current career goal responded differently than other participants, and these participants are often not included in NSF and other organizations definition of STEM, we chose to remove those 53 participants from the analysis altogether, giving a final sample size of 905. 
Table 1. Number of Students Selecting each Career Goal

\begin{tabular}{lcc}
\hline Career Goal & Number & Percent of Sample \\
\hline Non-STEM (e.g. lawyer, business person, social & 422 & 47 \\
scientist, English/language arts specialist) & & \\
STEM & & 3 \\
$\quad$ Mathematician & 25 & 9 \\
Life/earth/environmental scientist & 83 & 4 \\
Physical scientist & 32 & 28 \\
Engineer & 252 & 9 \\
Computer scientist, IT & 80 & 53 \\
\hline STEM Total & 472 & \\
\hline
\end{tabular}

\section{Research Question 3}

In order to answer the third research question a correlation test was conducted between mathematics identity and strength of gender identification for each gender. A proxy for mathematics identity was used as appropriate based on results from a previous analysis (Cribbs et al., 2015). The proxy included students' self-perceptions as they relate to the constructs: recognition and interest. The mathematics identity proxy was calculated by taking the average of these items and then standardizing the variable to have a mean of 0 and a standard deviation of 1 . The Cronbach's alpha for the mathematics identity construct was 0.92. The strength of gender identification proxy was calculated by taking the average of the four items and then standardizing the variable to have a mean of 0 and a standard deviation of 1. The Cronbach's alpha for the strength of gender identification construct was 0.90 .

\section{Results}

\section{Research Question 1}

Results for research question 1, 'Do women who pursue STEM careers identify with different self-identified personality attributes than women who do not pursue STEM careers?', indicate differences between female students who selected a STEM versus a Non-STEM career goal. Results of significant items along with the corresponding mean, standard error, and level of significance are shown in Table 2.

Table 2. Results of Wilcoxon Rank Sum test for female students, STEM versus NonSTEM

\begin{tabular}{lllc}
\hline Attribute & $\begin{array}{l}\text { STEM(n=102) } \\
\text { Mean (SE) }\end{array}$ & $\begin{array}{l}\text { Non-STEM (n=234) } \\
\text { Mean (SE) }\end{array}$ & Sig. \\
\hline Likes to go against societal norms & $4.80(0.15)$ & $4.01(0.09)$ & $* * *$ \\
Inquisitive & $5.48(0.12)$ & $5.15(0.08)$ & $* *$ \\
Lazy & $3.87(0.17)$ & $3.35(0.10)$ & $* *$ \\
Able to be 'one of the guys' & $5.11(0.15)$ & $4.73(0.11)$ & $*$ \\
Is a leader & $5.11(0.13)$ & $5.36(0.09)$ & $\dagger$ \\
Relates well to women & $5.17(0.13)$ & $5.44(0.09)$ & $\dagger$ \\
Shows concern for people's well-being & $5.66(0.13)$ & $5.91(0.08)$ & $\dagger$ \\
Creative & $5.09(0.15)$ & $4.71(0.11)$ & $\dagger$ \\
Expresses individuality & $5.70(0.11)$ & $5.44(0.08)$ & $\dagger$ \\
Analytical & $5.37(0.11)$ & $5.09(0.08)$ & $\dagger$ \\
\hline
\end{tabular}


Results indicate significant differences between STEM and Non-STEM participants. Female students pursuing a STEM career are more likely to identify themselves as 'Likes to go against societal norms' than female students not pursuing a STEM career. Likewise, female students pursuing a STEM career are more likely to identify themselves as 'Inquisitive', 'Lazy', and 'Able to be 'one of the guys' than female students not pursuing a STEM career. With regards to the attribute 'Lazy', it is important to note that both groups marked themselves low on this attribute, however, Non-STEM female students marked themselves even lower than STEM female students. Marginal differences were also noted in the table, as societal norms related to gender and career goals may be subtle. Results indicate that female students pursuing a STEM career are more likely to identify themselves as 'Creative', 'Expresses individuality', and 'Analytical' than female students not pursuing a STEM career. However, female students pursuing a STEM career are less likely to identify themselves as 'Is a leader', 'Relates well to women', and 'Shows concern for people's well-being' than female students not pursuing a STEM career.

\section{Research Question 2}

Results for research question 2, 'Do men who pursue STEM careers identify with different self-identified personality attributes than men who do not pursue STEM careers?', indicate differences between male students who selected a STEM versus a Non-STEM career goal. Results of significant items along with the corresponding mean, standard error, and level of significance are shown in Table 3.

Table 3. Results of Wilcoxon Rank Sum test for male students, STEM versus NonSTEM

\begin{tabular}{llll}
\hline Attribute & $\begin{array}{l}\text { STEM (n=376) } \\
\text { Mean (SE) }\end{array}$ & $\begin{array}{l}\text { Non-STEM (n=193) } \\
\text { Mean (SE) }\end{array}$ & Sig. \\
\hline Passionate about ones' major & $5.53(0.07)$ & $4.99(0.10)$ & $* * *$ \\
Thinks logically & $5.80(0.06)$ & $5.51(0.08)$ & $* * *$ \\
Masculine & $4.98(0.07)$ & $5.27(0.08)$ & $* *$ \\
Creative & $4.95(0.07)$ & $4.68(0.11)$ & $* *$ \\
Inquisitive & $5.16(0.07)$ & $4.94(0.09)$ & $*$ \\
Athletic & $5.12(0.08)$ & $5.40(0.11)$ & $*$ \\
Competitive & $5.61(0.07)$ & $5.79(0.10)$ & $\dagger$ \\
I do not mind sacrificing personal time & $4.62(0.08)$ & $4.90(0.10)$ & $\dagger$ \\
for my studies & & & \\
\hline$\dagger \mathrm{p}<0.10 * \mathrm{p}<0.05 * * \mathrm{p}<0.01 \quad * * * \mathrm{p}<0.001$ & & &
\end{tabular}

Results indicate significant differences between STEM and Non-STEM participants. Male students pursuing a STEM career are more likely to describe themselves as 'Passionate about ones' major', 'Thinks logically', 'Creative', and 'Inquisitive' than male students not pursuing a STEM career. However, male students pursuing a STEM career were less likely to identify themselves as 'Masculine' and 'Athletic' than male students not pursuing a STEM career. Marginal differences indicate that male students pursuing a STEM career are less likely to describe themselves as 'Competitive' and 'I do not mind sacrificing personal time for my studies" than male students not pursuing a STEM career.

\section{Research Question 3}

To answer research question 3, 'Is the strength of college students' gender identification correlated with their mathematics identity?', a correlation test was performed between the two variables. Results are shown in Table 4. 
Table 4. Results for Correlation Test, Strength of Gender Identification and Mathematics Identity

\begin{tabular}{ll}
\multicolumn{1}{c}{$\begin{array}{l}\mathrm{N}=369 \\
\text { Females }\end{array}$} & $\begin{array}{l}\text { Mathematics } \\
\text { Identity }\end{array}$ \\
\hline $\begin{array}{l}\text { Gender } \\
\text { Identification }\end{array}$ & 0.095 \\
\hline
\end{tabular}

\begin{tabular}{ll}
\multicolumn{1}{c}{$\begin{array}{c}\mathrm{N}=589 \\
\text { Males }\end{array}$} & $\begin{array}{l}\text { Mathematics } \\
\text { Identity }\end{array}$ \\
\hline $\begin{array}{l}\text { Gender } \\
\text { Identification }\end{array}$ & $0.100^{*}$ \\
\hline
\end{tabular}

Although results indicate a statistical significance between the strength of gender identification and mathematics identity for male students, the correlation coefficient is extremely small for both male and female students. Furthermore, a scatter plot of each of the samples did not highlight a non-linear relationship either.

\section{Discussion}

Due to our prior research findings, one question we wanted to explore more deeply in this study was whether or not individuals choosing STEM careers have different self-identified personality attributes than individuals not choosing STEM careers. Knowing that certain personality attributes are stereotypically associated with each gender (Piatek-Jimenez, Cribbs, \& Gill, 2018), we chose to analyze the male and female students' responses separately.

In our analysis, we found that some statistically significant items were the same, or similar, for both genders. For example, both male and female college students intending to enter STEM careers were more likely to identify as 'Creative' and 'Inquisitive' than college students not pursuing STEM careers. Furthermore, female STEM students were more likely to identify with 'Analytical' and male STEM students were more likely to identify with 'Thinks logically' than the Non-STEM students of their gender. While these two selfidentified personality attributes are different, they are certainly related to each other, and are both often associated with STEM careers (Wright, 1994). We also want to note that although creativity may not always be perceived as important in STEM fields as compared to some Non-STEM fields, such as an artist, writer, or musician, it is a vital component in many STEM-based careers (Cropley, 2016; Kaufman \& Baer, 2005). Therefore, given that these are all personality attributes that are beneficial to those in STEM careers, these findings may not be surprising. Moreover, since most of these personality attributes are currently classified by college students as 'Gender Neutral' with only 'Creative' being seen as 'Slightly Female Dominate' (Piatek-Jimenez et al., 2018), it may also not be surprising that these were common findings amongst both the male and female participants in this study.

Despite the similarities found between the genders, we also found some self-identified personality attributes unique to each gender as well. For example, the women interested in STEM careers were more likely to report themselves as 'Likes to go against societal norms', "Able to be "one of the guys", and 'Expresses individuality' and were less likely to report themselves as 'Is a leader', 'Relates well to women', and 'Shows concern for people's wellbeing' than women not planning on STEM careers. These findings might be indicative of the male-dominated nature of these fields. In many cases, for women to enter a male-dominated field, they are going against societal norms and are expressing individuality. Furthermore, knowing that many of their future colleagues will likely be male, they may feel it is necessary to be perceived as 'one of the guys' to navigate the field successfully. Furthermore, women in STEM fields may not feel much like a leader, since men tend to dominate the leadership 
roles in those fields (Fassinger, 2008). Given the overall negative perceptions of women in leadership roles (Smith, Rosenstein, Nikolov, \& Chaney, 2019), women pursuing a degree in a male-dominated field may also feel added pressure to avoid being seen as a leader. Women interested in STEM fields might be less likely to report themselves as showing concern for people's well-being since many mathematics and science-based fields are perceived as less people-oriented and less likely to address societal problems as other Non-STEM fields (Piatek-Jimenez, 2007; Widnall, 2000).

The finding that the female students interested in STEM careers identified as more lazy than the female students not interested in STEM careers is a little harder to interpret. It is important to note that both groups of women did not identify as lazy (the mean score was less than 4, which was neutral), but that those interested in Non-STEM careers identified less with 'Lazy' than those who have STEM career goals. What we do not know, however, is whether the participants were thinking of the term 'Lazy' in terms of academics or in terms of physical activity. Furthermore, the interpretation may not have been consistent amongst the entire sample. Therefore, more research would need to be done in order to better understand the meaning behind this result.

Just as with the STEM female college students, there were self-identified personality attributes that were unique to the STEM male college students as well. For example, the male students interested in STEM careers were more likely to identify as 'Passionate about one's major' than the male students not interested in STEM careers. We view this finding to be consistent with the stereotype that mathematicians and scientists are obsessed with their work (Piatek-Jimenez, 2008; Picker \& Berry, 2000). Given that such stereotypes also include the belief that mathematicians and scientists tend to be male may be why this finding appeared amongst the male STEM students but not the female STEM students.

The male STEM students in our study were less likely to identify with the self-identified personality attributes 'Masculine', 'Athletic', and 'Competitive' than their Non-STEM peers. All three of these personality attributes are seen by college students as highly 'Male Dominate' attributes (Piatek-Jimenez et al., 2018). Although STEM fields tend to be male dominated, it appears that men selecting STEM career goals do not identify with these male dominate attributes. Given that mathematicians and scientists are often portrayed as not being very athletic (Lipsman, 2012) may relate to this finding.

We also found that the male STEM students in our study were less likely to identify with the phrase 'I do not mind sacrificing personal time for my studies' as compared to the male NonSTEM students. This finding surprised us given that STEM classes tend to be seen as demanding and time-consuming (Mohrig, 2004; Piatek-Jimenez, 2015). To better understand this finding, which was only marginally significant, more research would need to be done.

Therefore, with regards to research questions 1 and 2, we found that there are certain selfidentified personality attributes that individuals interested in STEM fields were more likely or less likely to identify with. Some of these attributes were common to both genders. These were attributes that would be useful to all students in STEM fields, such as being inquisitive and creative. We also found that certain self-identified personality attributes were unique to each gender. For example, for a woman who is interested in pursuing a male dominated field, having self-identified personality attributes such as going against societal norms and being able to be 'one of the guys' are attributes that may be beneficial to her in such a field, which may not be particularly important attributes for men entering male dominated fields. 
Furthermore, there are typically masculine attributes that men interested in STEM fields identify with less than men not interested in STEM fields, demonstrating that men interested in STEM fields do not necessarily identify with traditionally male stereotypes.

In addition to self-identified personality attributes, we were also interested to understand the role that the strength of one's gender identification plays on their mathematics identity. Given that STEM fields tend to be male-dominated, and that mathematics identity is predictive of STEM careers, we hypothesized that there would be a negative correlation between mathematics identity and the strength of one's gender identification for women and a positive correlation between the two variables for men. Our results demonstrate that this is not the case. We found there was virtually no correlation between mathematics identity and strength of gender identification for either gender. What this result tells us is that regardless of gender, whether or not an individual identifies strongly with their gender does not relate to whether or not they have a strong mathematics identity. These appear to be completely separate constructs. We believe that this finding is hopeful, in that it suggests that women who believe that being a woman is very important to her identity are no less likely to have a strong mathematics identity than women in general.

\section{Concluding Thoughts}

In this study, we found some differences in self-identified personality attributes between individuals with STEM and Non-STEM career goals. While some of the differences between STEM and Non-STEM students were the same or similar amongst men and women, there were some notable differences. For example, the women with STEM career goals more strongly identified with certain attributes that would be especially useful to women in maledominated professions, such as being able to be 'one of the guys' and liking to go against societal norms. Furthermore, they were less likely to identify with other attributes which are often seen as female-dominate attributes, such as showing concern for people's well-being and being able to relate well to women (Piatek-Jimenez et al., 2018). The male students with STEM career goals did not stand apart from the male Non-STEM students on these personality attributes. Therefore, it seems probable that either the women with STEM career goals have strengthened certain personality attributes within themselves over the years to aid themselves in being more successful and accepted within their chosen STEM fields, or the women who do not identify with these attributes have selected themselves out of such career paths, or a combination of both.

Either way, this work suggests that underlying gender stereotypes about STEM careers may limit certain women from pursuing these fields or encourage other women to alter who they are (either consciously or subconsciously) to fit into these fields. Rather than feeling a need to conform to societal perceptions about who belongs in STEM fields, we feel it is important to change the perceptions of these fields and associated spaces (e.g., college programs, professional settings). One way to move this conversation forward is by highlighting the benefit of having diverse identities within a field. Innovation and technical advancements are more likely to occur when explored within diverse spaces. As such, if the ultimate goal is to move the STEM fields forward, it is important to be inviting to individuals, both men and women, with a variety of personality attributes.

Recent research in the field notes the need to think differently about how STEM fields can create more inclusive spaces for diverse groups of individuals. This would serve to increase the number of individuals entering these fields, particularly those who have been traditionally 
excluded from these spaces. Godwin and colleagues (2021) theorize that rather than asking students to conform to the "ways of being, thinking, and knowing" by dominate cultures, STEM fields should change their climate and culture to not only attract but also retain students in these fields (p. 3).

\section{Limitations}

It is important to keep in mind that these results are not necessarily generalizable given the relatively small sample size and inclusion of only two universities in the United States. Future research may explore if results vary across different regions and settings. In addition, the survey responses do not provide detail for why particular differences were found. Future qualitative research could provide further insight.

\section{Ethical Approval}

All procedures performed in studies involving human participants were in accordance with the ethical standards of the institutional and/or national research committee (Institutional Review Board, 661808-1) and with the 1964 Helsinki declaration and its later amendments or comparable ethical standards.

\section{References}

Atkinson, R. (2013). A short and long-term solution to America's STEM crisis. The Hill, from http://thehill.com/blogs/congress-blog/technology/287435-a-short-and-long-term-solution-to-americas-stemcrisis.

Augustine, N., Barrett, C., Cassel, G., Grasmick, N., Holliday, C., Jackson, S.A., Jones, A.K., Levin, R., Mote, C.D., Murray, C., O’Donnell, P., Raymond, L.R., Richardson, R.C., Vagelos, P., Vest, C.M., Whitesides, G.M., \& Zare, R.N. (2010). Rising above the gathering storm revisited: Rapidly approaching category 5. Washington, DC: The National Academics Press.

Buddeberg-Fischer, B., Klaghofer, R., Abel, T., \& Buddeberg, C. (2006). Swiss residents' speciality choicesimpact of gender, personality traits, career motivation and life goals. BMC Health Services Research, 6(1), 137.

Cobb, P., \& Hodge, L. L. (2010). Culture, identity, and equity in the mathematics classroom. In A journey in mathematics education research (pp. 179-195). Springer, Dordrecht.

Cropley, D. H. (2016). Creativity in engineering. In G. E. Corazza \& S. Agnoli (eds.) Multidisciplinary Contributions to the Science of Creative Thinking (pp. 155-173). Singapore: Springer.

Cribbs, J., Hazari, Z., Sadler, P.M., \& Sonnert, G. (2015). Establishing an explanatory framework for mathematics identity. Child Development. 86(4), 1048-1062.

Cribbs, J., Cass, C., Hazari, Z., Sadler, P., \& Sonnert, G. (2016). Mathematics and student persistence in engineering. International Journal of Engineering Education. 32(1), 163-171.

Cundiff, J. L., Vescio, T. K., Loken, E., \& Lo, L. (2013). Do gender-science stereotypes predict science identification and science career aspirations among undergraduate science majors?. Social Psychology of Education, 16(4), 541-554.

Ely, R. J. (1995). The power in demography: Women's social constructions of gender identity at work. Academy of Management journal, 38(3), 589-634.

Epstein, D., Mendick, H., \& Moreau, M. P. (2010). Imagining the mathematician: Young people talking about popular representations of maths. Discourse: Studies in the Cultural Politics of Education, 31(1), 45-60.

Fassinger, R. E. (2008). Workplace diversity and public policy: Challenges and opportunities for psychology. American Psychologist, 63(4), 252-268.

Fralick, B., Kearn, J., Thompson, S., \& Lyons, J. (2009). How middle schoolers draw engineers and scientists. Journal of Science Education and Technology, 18(1), 60-73.

Gelman, A., \& Hill, J. (2006). Data analysis using regression and multilevel/hierarchical models. Cambridge university press. 
Godwin, A., Benedict, B. S., Rohde, J., Clements, H. R., Perkins, H. L., Melo, J. M., \& Castillo, A. L. (2021, July). CAREER: Learning from Students' Identity Trajectories to Actualize Latent Diversity. In 2021 ASEE Virtual Annual Conference Content Access.

Godwin, A., Potvin, G., Hazari, Z., \& Lock, R. (2016). Identity, critical agency, and engineering: An affective model for predicting engineering as a career choice. Journal of Engineering Education, 105(2), 312-340.

Gunderson, E. A., Ramirez, G., Levine, S. C., \& Beilock, S. L. (2012). The role of parents and teachers in the development of gender-related math attitudes. Sex Roles, 66(3-4), 153-166.

Hazari, Z., Sonnert, G., Sadler, P. M., \& Shanahan, M. C. (2010). Connecting high school physics experiences, outcome expectations, physics identity, and physics career choice: A gender study. Journal of Research in Science Teaching, 47(8), 978-1003.

Helwig, R., Anderson, L., \& Tindal, G. (2001). Influence of elementary student gender on teachers' perceptions of mathematics achievement. The Journal of Educational Research, 95(2), 93-102.

Hill, C., Corbett, C., \& St Rose, A. (2010). Why so few? Women in science, technology, engineering, and mathematics. Washington, DC: American Association of University Women.

Jones, B. D., Ruff, C., \& Paretti, M. C. (2013). The impact of engineering identification and stereotypes on undergraduate women's achievement and persistence in engineering. Social Psychology of Education, 16(3), 471-493.

Kaufman, J. C., \& Baer, J. (Eds.). (2005). Creativity across domains: Faces of the muse. Psychology Press.

Kiefer, A. K., \& Sekaquaptewa, D. (2007). Implicit stereotypes, gender identification, and math-related outcomes: A prospective study of female college students. Psychological Science, 18(1), 13-18.

Langdon, D., McKittrick, G., Beede, D., Khan, B., \& Doms, M. (2011). STEM: Good jobs now and for the future. U.S. Department of Commerce, Economics and Statistics Administration, from http://files.eric.ed.gov/fulltext/ ED522129.pdf

Lipsman, R. (2012). The math gene: A ticket to wealth or nerdiness?. NOTICES OF THE AMS, 59(11), 1518.

Lock, R. M., Hazari, Z., \& Potvin, G. (2019). Impact of out-of-class science and engineering activities on physics identity and career intentions. Physical Review Physics Education Research, 15(2), 020137.

Luhtanen, R., \& Crocker, J. (1992). A collective self-esteem scale: Self-evaluation of one's social identity. Personality and Social Psychology Bulletin, 18(3), 302-318.

Luyckx, K., Soenens, B., \& Goossens, L. (2006). The personality-identity interplay in emerging adult women: Convergent findings from complementary analyses. European Journal of Personality, 20(3), 195-215.

Makarova, E., Aeschlimann, B., \& Herzog, W. (2019). The gender gap in STEM fields: The impact of the gender stereotype of math and science on secondary students' career aspirations. In Frontiers in Education (Vol. 4, p. 60). Frontiers.

Marginson, S., Tytler, R., Freeman, B., \& Roberts, K. (2013). STEM: Country comparisons. Australian Council of Learned Academies, https://acola.org/wp-content/uploads/2018/12/saf02-stem-country-comparisons.pdf

Mohrig, J. R. (2004). The problem with organic chemistry labs. Journal of Chemical Education, 81(8), 10831085 .

National Academy of Sciences, National Academy of Engineering, \& Academies, Institute of Medicine of the National (2005). Rising above the gathering storm: Energizing and employing America for a brighter economic future. Washington, DC: Committee on Prospering in the Global Economy of the 21st Century, Committee on Science, Engineering, and Public Policy.

National Science Foundation, National Center for Science and Engineering Statistics. (2019). Women, Minorities, and Persons with Disabilities in Science and Engineering: 2019. Special Report NSF 19-304. Alexandria, VA, from https://www.nsf.gov/statistics/wmpd.

Organisation for Economic Co-operation and Development. (2011). Science, technology and industry scoreboard 2011. OECD Publishing, Paris.

Organisation for Economic Co-operation and Development. (2012). Education at a glance 2012: OECD indicators. OECD Publishing, Paris.

Piatek-Jimenez, K. (2007). May I Help You? Public Service as a Factor in Career Selection. Proceedings of the Twenty-Ninth Annual Conference of the North American Chapter of the International Group for the Psychology of Mathematics Education.

Piatek-Jimenez, K. (2008). Images of mathematicians: A new perspective on the shortage of women in mathematical careers. ZDM - The International Journal on Mathematics Education, 40(4), 633-646.

Piatek-Jimenez, K. (2015). On the persistence and attrition of women in mathematics, Journal of Humanistic Mathematics, 5(1), 3-54.

Piatek-Jimenez, K., \& Cribbs, J., Gill, N. (2018). College students' perceptions of gender stereotypes. International Journal of Science Education, 40(12), 1432-1454.

Picker, S. \& Berry, J. (2000). Investigating pupils' images of mathematicians, Educational Studies in Mathematics, 43(1), 65-94. 
R Core Team (2016). R: A language and environment for statistical computing. R Foundation for Statistical Computing, Vienna, Austria. URL https://www.R-project.org/.

Schmader, T. (2002). Gender identification moderates stereotype threat effects on women's math performance. Journal of Experimental Social Psychology, 38(2), 194-201.

Smith, D. G., Rosenstein, J. E., Nikolov, M. C., \& Chaney, D. A. (2019). The power of language: Gender, status, and agency in performance evaluations. Sex Roles, 80(3-4), 159-171.

Steele, J. (2003). Children's gender stereotypes about math: The role of stereotype stratification. Journal of Applied Social Psychology, 33(12), 2587-2606.

Widnall, S. E. (2000). Digits of Pi: Barriers and enablers for women in engineering. The Bridge. National Academy of Engineering, 30(3/4), 14-18.

Wright, P., (1994). Introduction to engineering. 2nd ed. New York: Wiley. 